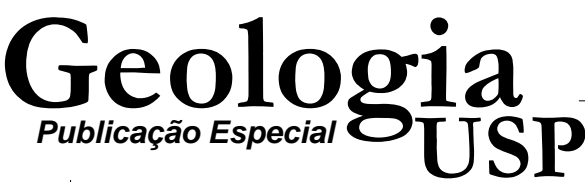

\section{O Que os Professores Pensam Sobre Geociências e Educação Ambiental? (Levantamento Exploratório de Concepções de Professores de Ribeirão Preto, SP)}

\author{
Pedro Wagner Gonçalves' (pedrog@ige.unicamp.br) e Natalina Aparecida Laguna Sicca² \\ 'Departamento de Geociências Aplicadas ao Ensino - Instituto de Geociências - UNICAMP \\ Caixa Postal 6.152, CEP 13083-970, Campinas, SP, BRA
}

${ }^{2}$ Programa de Pós-Graduação em Educação, Centro Universitário Moura Lacerda, Ribeirão Preto, SP, BRA

Recebido em 18 de novembro de 2004; aceito em 28 de março de 2005

Palavras-chave: ensino de Geociências, ensino médio, educação ambiental, contextualização no ensino.

\section{RESUMO}

Este texto expõe o que professores do ensino médio pensam sobre contextualização no ensino, Geociências e suas mútuas inter-relações. Foi feito levantamento exploratório junto a professores de Geografia, Biologia, Física e Química da região de Ribeirão Preto para conhecer a opinião desses professores sobre questões ambientais e avaliar as condições para desenvolvimento de educação continuada. O estudo revela que os professores desenvolvem ensino contextualizado mas não aprofundam suficientemente o pensamento crítico e as possibilidades da educação ambiental. Apesar das oportunidades abertas pela legislação educacional e pela tradição cultural, os professores encontram barreiras para desenvolver a integração das disciplinas. Defendemos que uma dificuldade adicional é o baixo domínio das Ciências da Terra que seria uma possibilidade para integrar conteúdos de diferentes áreas sob uma perspectiva ambiental.

Keywords: teaching of Earth Sciences, secondary school, environmental education, situated learning.

\section{ABSTRACT}

This paper shows what secondary school teachers think about situated learning, the Earth Sciences, and the relationships between the two. A survey of what Geography, Biology, Physics and Chemistry teachers of the Ribeirão Preto area think about environmental problems was undertaken to evaluate what needs to be done for continuing education. The study shows that teachers do practice situated learning but they are do not deepen either the critical discussions or the possibilities of environmental education. In spite of the opportunities given by educational legislation, and cultural traditions, the teachers encounter obstacles to integrate the subjects. We believe that an additional difficulty is the poor command of Earth Science subjects which would allow the integration of different areas within an environmental perspective. 


\section{INTRODUÇÃO}

Este trabalho relata parte de um projeto de pesquisa que vimos desenvolvendo na Oficina Pedagógica de uma Diretoria de Ensino do Estado de São Paulo para compreender o processo curricular no ensino médio. Ao mesmo tempo, pretendemos construir um espaço interdisciplinar de debate sobre o conhecimento escolar, caracterizado por meio de uma pesquisa colaborativa entre pesquisadores da Universidade, assistentes técnicos da Diretoria de Ensino e professores da rede estadual.

Mais especificamente, no âmbito deste texto, pretendemos, tratar como o discurso oficial para o ensino médio, que preconiza como eixos do currículo a interdisciplinaridade e a contextualização, está sendo interpretado pelos professores na prática escolar; principalmente procura compreender como a Geologia pode contribuir para o desenvolvimento do contexto ambiental no currículo.

Apoiados em Gimeno Sacristán e Pérez Gómez (1998) concebemos o currículo numa perspectiva processual, que se dá em diferentes contextos, desde o mais amplo das decisões políticas e administrativas que estabelecem o jogo do sistema curricular até o contexto escolar, onde se dá a realização das práticas ou ações cotidianas.

Pacheco (2003, p. 15) acrescenta que os atores curriculares, sobretudo aqueles que se situam no contexto da escola, são produtores de discursos políticos que legitimam e atribuem significado ao cotidiano escolar.

Para analisarmos como os atores participam da construção do currículo, temos que nos voltar para as macro e micropolíticas. Nos limites deste trabalho trataremos o plano das micropolíticas, ou seja, "o lugar das escolas, dos professores e dos alunos na configuração prática do currículo" (Pacheco, 2003, p. 17). E dentro das micropolíticas, nos detemos num ponto crucial neste âmbito, ou seja: como os professores compreendem o discurso oficial no tocante a contextualização, ao estabelecer vínculos entre Ciência e vida, especialmente quando veiculam problemas ambientais.

\section{O CURRÍCULO PRESCRITO: O DISCURSO OFICIAL VOLTADO PARA O ENSINO MÉDIO}

Durante a década de 1990, o Brasil foi palco de profunda reforma educacional que alcançou todos os níveis de ensino. $\mathrm{O}$ aparato legal foi substancialmente modificado com implicações na vida de alunos e professores. A Lei de Diretrizes e Bases da Educação (LDB), promulgada em 1996, trouxe alterações na organização dos diferentes níveis de ensino redirecionando inclusive suas finalidades de acordo com as novas identidades a serem produzidas. Interessa-nos, neste momento, o ensino médio (destinado a alunos de 15 a 18 anos).

No sentido de implementar a política educacional, em 1998, foram aprovados os Parâmetros Curriculares Nacionais para o Ensino Médio (PCNEM), as Diretrizes Curriculares Nacionais para o Ensino Médio e o Parecer CEB nº 15/98. O discurso oficial caracteriza este nível de ensino como etapa final da escolarização básica, tendo como finalidades "desenvolver o educando, assegurar-lhe a formação comum indispensável para o exercício da cidadania e fornecer-lhe meios para progredir no trabalho e em estudos posteriores” (Art. 22, Lei 9394/96). Seu currículo deve preparar para o trabalho e para a cidadania. Os documentos admitem que as competências exigidas para o exercício da cidadania e para as atividades produtivas são idênticas (Brasil, 1999).

Os PCNEM introduzem significativa mudança curricular. Anteriormente o currículo era orientado por meio de Propostas Curriculares, de âmbito estadual, organizado por disciplinas (Português, Matemática, Inglês, Geografia, História, Química, Física e Biologia) - e, agora, passa a ser orientado por parâmetros de âmbito federal organizados em áreas de conhecimento (Área de Ciências Naturais, Matemática e suas Tecnologias; Área de Ciências Humanas e suas Tecnologias; Área de Comunicação, Artes e suas Tecnologias). Indicam ainda que essas devem ter como eixo a contextualização e interdisciplinaridade.

Nas Diretrizes Curriculares consta que o contexto principal a ser priorizado no ensino médio é o do trabalho, considerado importante para o exercício da cidadania; inclui adicionalmente a vida pessoal, o cotidiano, a convivência e as questões ligadas ao meio ambiente, corpo e saúde.

Sampaio (2002, p. 11) nos indica que há traços bastante sedimentados na tradição escolar:

“a estruturação por disciplinas, a grande extensão dos programas, a autoridade dos manuais e sua função de guias para seleção, seqüencia, dosagem e exercitação das noções; por outro lado, a ênfase na memória $e$ repetição; e ainda, como elemento regulador da disciplina, da ordem, dos comportamentos da evolução dos alunos na escolaridade, as provas, os exames e a reprovação”.

Se de um lado, o discurso oficial inova ao propor a organização por áreas de conhecimento e ao considerar a importância da interdisciplinaridade e contextualização para ampliar as inúmeras possibilidades de interação entre disciplinas e entre áreas, de outro, ao analisarmos as políticas curriculares no Brasil, desde a década de 1930, podemos perceber algumas continuidades. Estas, entretanto, exigem um exame mais atento e a análise dos currículos nos referidos contextos de elaboração.

O discurso oficial voltado para o ensino secundário no Brasil, pelo menos desde a década de 1930, com a promul- 
gação da Reforma Francisco Campos, advoga a importância de relacionar o conhecimento científico com a vida (Senna, 1939). Porém, na década de 1980 , nas Propostas Curriculares do Estado de São Paulo, ao mesmo tempo em que a introdução do cotidiano passou a ser central na organização e seleção dos conteúdos curriculares da época (Palma Filho, 1989), percebemos uma concepção diferente das anteriores para o papel da contextualização no ensino.

Sicca (2003) defende que a transposição didática prevista para as aulas de química, na década de 1980, deveria ter como um de seus princípios orientadores a introdução do cotidiano no ensino. Nesta perspectiva, o aluno precisava reinterpretar seu cotidiano, a partir da compreensão da Ciência e de sua aplicação, para perseguir uma perspectiva crítica voltada para a transformação da sociedade.

Barretto (1998, p. 10), ao se referir às Propostas Curriculares elaboradas na década de 1980, no Estado de São Paulo, advoga: "o currículo cuidaria que a educação transcendesse os limites do vivido e propiciasse o domínio da cultura capaz de ultrapassar os interesses regionais ou de grupo e classes, possuindo características universais”.

Apesar de certa continuidade, as Diretrizes Curriculares para o ensino médio e os PCNEM inovam ao redefinir a contextualização e ao associá-la à interdisciplinaridade, ao mesmo tempo em que atrelam a contextualização a uma perspectiva eficientista. Segundo Lopes (2003, p. 398), rapidamente "vem se fazendo uma substituição do conceito de cotidiano $e$ valorização dos saberes populares pelo conceito de contextualização, muitas vezes havendo a suposição de que se trata do mesmo enfoque educacional. Desconsidera-se que a contextualização é um dos processos de formação de competências necessárias ao trabalho na sociedade globalizada e à inserção no mundo tecnológico”.

A concepção de ciências preconizada pela legislação, em largos traços, coincide com enfoques e abordagens defendidos por pesquisadores dedicados ao Ensino de Ciências e de Geologia. Defende-se a idéia de Ciências para todos vinculada à necessidade do entendimento da natureza do conhecimento científico (p. ex.: Robinson, 1998; Hurd, 1998; Matthews, 1997) e que tal natureza necessita ser vinculada com implicações sociais e tecnológicas (p. ex.: McGinnis e Simmons, 1999; Solbes e Vilches, 1997). Na mesma valorização de aspectos práticos, tecnológicos, sistêmicos e éticos encontramos Amaral (1995), Anguita (1996), Bezzi (1999) e Rojero (2000); todos, de certa maneira, preconizam os aspectos ambientais do ensino de estudos da Terra.

Por outro lado, em diversos debates, reuniões etc., com professores da rede pública de ensino (em programas para a formação continuada), percebemos que a contextualização faz parte dos ideários docentes. Como teria sido traduzida pelos professores a contextualização? Teriam os professores condições para implementá-la no ensino médio elegendo-a como um dos eixos do currículo? O discurso do professor aproximaria do discurso oficial e das perspectivas da pesquisa educacional de ensino de Ciências?

\section{RESULTADOS}

\section{Características dos professores da região de Ribeirão Preto}

A região de Ribeirão Preto aqui considerada engloba 12 municípios do Estado de São Paulo, onde vivem cerca de 700 mil habitantes (segundo SEADE, 2005). Possui 52 escolas com nível médio do sistema estadual de ensino. Adotou-se como área de abrangência a jurisdição da Diretoria de Ensino da Região de Ribeirão Preto, que compreende os seguintes municípios: Altinópolis, Barrinha, Brodósqui, Cajuru, Cássia dos Coqueiros, Cravinhos, Dumont, Guariba, Guatapará, Jaboticabal, Jardinópolis, Luis Antonio, Monte Alto, Pitangueiras, Pontal, Pradópolis, Ribeirão Preto, Santa Cruz da Esperança, Santa Rosa do Viterbo, Santo Antonio da Alegria, São Simão, Serra Azul, Serrana, Sertãozinho e Taquaral.

O levantamento realizado até o momento foi feito com 169 professores das disciplinas Biologia, Física, Geografia e Química. Os questionários foram respondidos entre a segunda quinzena de maio e durante o mês de junho de 2003.

Não há dados seguros sobre o número exato de professores que atuam na região. A mobilidade e substituição de professores é um elemento que permanentemente atua na rede escolar estadual. A dificuldade persiste quando tentamos obter o número exato de professores por disciplina. Em virtude disso, foi feita uma estimativa empírica para avaliar qual é o universo de cada uma das disciplinas examinadas (resultados são apresentados na Tabela 1).

Nos quatro universos pesquisados (professores de Biologia, Física, Geografia e Química) a amostra corresponde a mais de metade do total estimado de professores da região. Embora isso não atribua representatividade para as amostras, revela a opinião de parcela considerável dos professores de cada disciplina.

Quase a totalidade dos docentes que responderam ao questionário é graduada (Tabela 1). Em parte considerável dos casos, os professores são formados na disciplina que ministram mas chama atenção a presença de profissionais que ministram disciplinas aparentemente muito distantes de sua formação (p. ex.: um professor de Biologia declarou ter somente o curso de nível médio de Música). Chama atenção o pequeno número de professores de Física habilitados nesta disciplina (Tabela 1). Ao mesmo tempo, parcela dos professores possuem formação academicamente muito qualificada: é considerável o número de professores de Biologia e Química que possuem mestrado ou doutorado (Tabela 1). 
Tabela 1. Distribuição dos professores da Diretoria de Ensino de Ribeirão Preto segundo disciplina e formação acadêmica (número absoluto da amostra e porcentagem do universo estimado por disciplina). (1) Número estimado de professores da disciplina. (2) Porcentagem sobre o número estimado. (3) Possui graduação na disciplina que ministra. (4) Possui formação fora da disciplina que ministra. (5) Porcentagem dentro da amostra de respondentes. Fonte: Diagnóstico "Perfil do Professor de nível médio da região de Ribeirão Preto".

\begin{tabular}{|c|c|c|c|c|c|c|c|c|}
\hline \multirow[b]{2}{*}{ Perfil do professor } & \multicolumn{2}{|c|}{ Biologia } & \multicolumn{2}{|c|}{ Física } & \multicolumn{2}{|c|}{ Química } & \multicolumn{2}{|c|}{ Geografia } \\
\hline & $\begin{array}{l}\text { Números } \\
\text { absolutos }\end{array}$ & $\%$ & $\begin{array}{l}\text { Números } \\
\text { absolutos }\end{array}$ & $\%$ & $\begin{array}{l}\text { Números } \\
\text { absolutos }\end{array}$ & $\%$ & $\begin{array}{l}\text { Números } \\
\text { absolutos }\end{array}$ & $\%$ \\
\hline Estimativa do universo ${ }^{(1)}$ & 58 & - & 55 & - & 55 & - & 60 & - \\
\hline Respondentes $^{(2)}$ & 41 & 70,7 & 30 & 52,6 & 35 & 64,0 & 46 & 76,7 \\
\hline Habilitado ${ }^{(3)}$ & 20 & 48,8 & 6 & 20,0 & 29 & 82,9 & 22 & 47,8 \\
\hline Não habilitado ${ }^{(4)}$ & 4 & 9,6 & 12 & 40,0 & 5 & 14,3 & - & - \\
\hline Não respondeu ${ }^{(5)}$ & 17 & 41,5 & 12 & 40,0 & 2 & 6,9 & 19 & 41,3 \\
\hline Mestrado & 6 & 14,6 & - & - & 6 & 17,1 & - & - \\
\hline Doutorado & 3 & 7,3 & - & - & 1 & 5,7 & - & - \\
\hline
\end{tabular}

\section{A contextualização no ensino médio}

Os professores de Biologia são categóricos em afirmar que freqüentemente relacionam os temas de seu programa aos fatos da realidade (Tabela 2). Tendência semelhante é encontrada nos professores de Geografia (Tabela 2). Por outro lado, a grande maioria dos professores de Física indica que freqüentemente relaciona os temas da Física com fatos da realidade - um nível de resposta muito mais baixo que os demais grupos (Tabela 2). Enquanto os professores de Química sugerem estar mais preocupados quanto ao quesito do que os de Física e menos do que os outros dois conjuntos.

Se por um lado os professores nas diferentes disciplinas afirmam que contextualizam o ensino, estes indicam em menor porcentagem que incentivam os alunos a estabelecer relações do conhecimento científico e a realidade (como mostra-se na Tabela 2).

Quase a totalidade dos professores de Geografia preocupam-se com funções econômicas e éticas das matérias de ensino (Tabela 2). Nos outros grupos pesquisados isso não se constitui como algo relevante na opinião dos professores (segundo dados expostos na mesma Tabela 2).

$\mathrm{Na}$ opinião da maioria dos professores das quatro disciplinas examinadas, seus alunos algumas vezes são capazes de aplicar os conhecimentos explorados em sala de aula para sua vida prática (Tabela 2). O mesmo nível de resposta foi encontrado para a capacidade dos estudantes de diferenciarem matérias científicas e realidade.

Os professores foram questionados sobre acidente sócio-ambiental ocorrido na Florestal Cataguazes em 29 de março de 2003. Isso serviu como uma espécie de controle quanto às preocupações de relacionar suas disciplinas e a realidade. Além disso, serviu para obter alguns indicadores de como são estabelecidos os nexos de conteúdos e fatos da atualidade veiculados intensamente pela imprensa.

Quase a totalidade dos professores de Geografia fizeram menção do acidente para seus alunos (Tabela 3). A grande maioria dos professores de Biologia também o fez. Quase dois terços dos professores de Química também comentaram o assunto com os alunos. Menos de metade dos professores de Física trataram o assunto com seus alunos.

Os professores que trataram o assunto permitem formar uma idéia dos aspectos que mais foram enfatizados e aqueles que foram menos mencionados pelos docentes a partir da lista previamente apresentada no questionário.

Para os docentes que trataram o assunto, os resíduos, a contaminação e o ciclo da água parecem ser os tópicos mais explorados pelos professores em suas aulas (Tabela 3). Por outro lado, a xenofobia foi o aspecto menos assinalado na opinião dos professores e pode-se dizer que parcela considerável dos docentes sequer chamou atenção para a existência de sócios estrangeiros na empresa (Tabela 3).

Estudos adicionais para aprofundamento do assunto estão entre os aspectos menos enfatizados pelos professores (exceção somente dos professores de Geografia) Tabela 3. O entendimento dos efeitos a médio e longo prazo da contaminação também não foram enfatizados, bem como procedimentos e raciocínios hipotéticos que ajudariam os alunos a compreender a natureza e os limites do conhecimento científico igualmente não ocuparam relevância nas exposições e debates conduzidos em aula. 
Tabela 2. Procedimentos didáticos mais adotados segundo a opinião dos professores da região de Ribeirão Preto, apresentado em números absolutos e porcentagem da amostra da disciplina em foco (Biologia, 41 respondentes; Geografia, 46; Física, 30 e Química, 35). F - freqüentemente. A - às vezes. N - nunca. NR - não respondeu. Porcentagens aproximadas. Fonte: Diagnóstico "Perfil do Professor de nível médio da região de Ribeirão Preto".

\begin{tabular}{|c|c|c|c|c|}
\hline Procedimentos / Disciplinas & $\mathbf{F}$ & A & $\mathbf{N}$ & NR \\
\hline \multicolumn{5}{|l|}{ Biologia } \\
\hline Procuro relacionar temas do programa com fatos da realidade. & $\begin{array}{c}40 \\
(97,0 \%) \\
\end{array}$ & $\begin{array}{c}1 \\
(2,4 \%)\end{array}$ & - & - \\
\hline $\begin{array}{l}\text { Em minhas aulas, incentivo os alunos a estabelecerem relações } \\
\text { entre modelos e realidade. }\end{array}$ & $\begin{array}{c}21 \\
(51,0 \%)\end{array}$ & $\begin{array}{c}18 \\
(44,0 \%) \\
\end{array}$ & $\begin{array}{c}1 \\
(2,4 \%)\end{array}$ & $\begin{array}{c}1 \\
(2,4 \%)\end{array}$ \\
\hline $\begin{array}{l}\text { Discuto com meus alunos a função social, econômica ou ética dos } \\
\text { temas desenvolvidos. }\end{array}$ & $\begin{array}{c}27 \\
(66,0 \%)\end{array}$ & $\begin{array}{c}13 \\
(32,0 \%)\end{array}$ & - & - \\
\hline $\begin{array}{l}\text { Após as aulas, meus alunos são capazes de usar explicações, } \\
\text { conceitos, modelos ensinados em sua vida prática. }\end{array}$ & $\begin{array}{c}8 \\
(20,0 \%) \\
\end{array}$ & $\begin{array}{c}28 \\
(68,0 \%) \\
\end{array}$ & - & $\begin{array}{c}1 \\
(2,4 \%)\end{array}$ \\
\hline $\begin{array}{l}\text { Após as aulas, meus alunos são capazes de estabelecer diferenças } \\
\text { entre explicações, modelos científicos e a realidade. }\end{array}$ & $\begin{array}{c}9 \\
(22,0 \%) \\
\end{array}$ & $\begin{array}{c}25 \\
(61,0 \%) \\
\end{array}$ & - & $\begin{array}{c}1 \\
(2,4 \%) \\
\end{array}$ \\
\hline \multicolumn{5}{|l|}{ Geografia } \\
\hline Procuro relacionar temas do programa com fatos da realidade. & $\begin{array}{c}41 \\
(89,0 \%) \\
\end{array}$ & - & - & $\begin{array}{c}5 \\
(11,0 \%) \\
\end{array}$ \\
\hline $\begin{array}{l}\text { Em minhas aulas, incentivo os alunos a estabelecerem relações } \\
\text { entre modelos e realidade. }\end{array}$ & $\begin{array}{c}35 \\
(83,0 \%) \\
\end{array}$ & $\begin{array}{c}9 \\
(21,0 \%) \\
\end{array}$ & - & $\begin{array}{c}2 \\
(4,3 \%) \\
\end{array}$ \\
\hline $\begin{array}{l}\text { Discuto com meus alunos a função social, econômica ou ética dos } \\
\text { temas desenvolvidos. }\end{array}$ & $\begin{array}{c}38 \\
(90,0 \%)\end{array}$ & $\begin{array}{c}5 \\
(12,0 \%)\end{array}$ & - & $\begin{array}{c}3 \\
(6,5 \%)\end{array}$ \\
\hline $\begin{array}{l}\text { Após as aulas, meus alunos são capazes de usar explicações, } \\
\text { conceitos, modelos ensinados em sua vida prática. }\end{array}$ & $\begin{array}{c}13 \\
(31,0 \%) \\
\end{array}$ & $\begin{array}{c}32 \\
(72,0 \%) \\
\end{array}$ & - & $\begin{array}{c}1 \\
(2,1 \%) \\
\end{array}$ \\
\hline $\begin{array}{l}\text { Após as aulas, meus alunos são capazes de estabelecer diferenças } \\
\text { entre explicações, modelos científicos e a realidade. }\end{array}$ & $\begin{array}{c}13 \\
(31,0 \%) \\
\end{array}$ & $\begin{array}{c}32 \\
(72,0 \%) \\
\end{array}$ & - & $\begin{array}{c}1 \\
(2,1 \%) \\
\end{array}$ \\
\hline \multicolumn{5}{|l|}{ Física } \\
\hline Procuro relacionar temas do programa com fatos da realidade. & $\begin{array}{c}22 \\
(73,0 \%) \\
\end{array}$ & $\begin{array}{c}4 \\
(13,0 \%) \\
\end{array}$ & - & $\begin{array}{c}4 \\
(13,0 \%) \\
\end{array}$ \\
\hline $\begin{array}{l}\text { Em minhas aulas, incentivo os alunos a estabelecerem relações } \\
\text { entre modelos e realidade. }\end{array}$ & $\begin{array}{c}13 \\
(43,0 \%) \\
\end{array}$ & $\begin{array}{c}11 \\
(36,0 \%) \\
\end{array}$ & $\begin{array}{c}4 \\
(13,0 \%) \\
\end{array}$ & $\begin{array}{c}2 \\
(10,0 \%) \\
(10 \%\end{array}$ \\
\hline $\begin{array}{l}\text { Discuto com meus alunos a função social, econômica ou ética dos } \\
\text { temas desenvolvidos. }\end{array}$ & $\begin{array}{c}13 \\
(43,0 \%)\end{array}$ & $\begin{array}{c}11 \\
(36,0 \%) \\
\end{array}$ & - & $\begin{array}{c}1 \\
(3,3 \%)\end{array}$ \\
\hline $\begin{array}{l}\text { Após as aulas, meus alunos são capazes de usar explicações, } \\
\text { conceitos, modelos ensinados em sua vida prática. }\end{array}$ & $\begin{array}{c}6 \\
(20,0 \%) \\
\end{array}$ & $\begin{array}{c}22 \\
(73,0 \%) \\
\end{array}$ & $\begin{array}{c}2 \\
(10,0 \%) \\
\end{array}$ & - \\
\hline $\begin{array}{l}\text { Após as aulas, meus alunos são capazes de estabelecer diferenças } \\
\text { entre explicações, modelos científicos e a realidade. }\end{array}$ & $\begin{array}{c}4 \\
(13,0 \%) \\
\end{array}$ & $\begin{array}{c}22 \\
(73,0 \%) \\
\end{array}$ & $\begin{array}{c}3 \\
(10,0 \%) \\
\end{array}$ & $\begin{array}{c}1 \\
(3,3 \%)\end{array}$ \\
\hline \multicolumn{5}{|l|}{ Química } \\
\hline Procuro relacionar temas do programa com fatos da realidade. & $\begin{array}{c}28 \\
(80,0 \%) \\
\end{array}$ & $\begin{array}{c}6 \\
(17,0 \%) \\
\end{array}$ & - & $\begin{array}{c}1 \\
(2,9 \%) \\
\end{array}$ \\
\hline $\begin{array}{l}\text { Em minhas aulas, incentivo os alunos a estabelecerem relações } \\
\text { entre modelos e realidade. }\end{array}$ & $\begin{array}{c}19 \\
(54,0 \%) \\
\end{array}$ & $\begin{array}{c}11 \\
(31,0 \%) \\
\end{array}$ & $\begin{array}{c}5 \\
(20,0 \%) \\
\end{array}$ & - \\
\hline $\begin{array}{l}\text { Discuto com meus alunos a função social, econômica ou ética dos } \\
\text { temas desenvolvidos. }\end{array}$ & $\begin{array}{c}15 \\
(29,0 \%) \\
\end{array}$ & $\begin{array}{c}17 \\
(49,0 \%) \\
\end{array}$ & $\begin{array}{c}3 \\
(8,5 \%)\end{array}$ & - \\
\hline $\begin{array}{l}\text { Após as aulas, meus alunos são capazes de usar explicações, } \\
\text { conceitos, modelos ensinados em sua vida prática. }\end{array}$ & $\begin{array}{c}11 \\
(31,0 \%) \\
\end{array}$ & $\begin{array}{c}23 \\
(66,0 \%) \\
\end{array}$ & $\begin{array}{c}1 \\
(2,9 \%) \\
\end{array}$ & - \\
\hline $\begin{array}{l}\text { Após as aulas, meus alunos são capazes de estabelecer diferenças } \\
\text { entre explicações, modelos científicos e a realidade. }\end{array}$ & $\begin{array}{c}7 \\
(20,0 \%) \\
\end{array}$ & $\begin{array}{c}27 \\
(77,0 \%) \\
\end{array}$ & $\begin{array}{c}1 \\
(2,9 \%)\end{array}$ & - \\
\hline
\end{tabular}


Tabela 3. Tratamento em sala de aula do acidente sócio-ambiental da Florestal Cataguazes, ocorrido em 29 de março de 2003, segundo a opinião dos professores. Organizado por disciplina. Apresentado em número absoluto e porcentagem da amostra de cada disciplina. Bio - professores de Biologia. Geo - professores de Geografia. Fís - professores de Física. Quí - professores de Química. Porcentagens aproximadas. Fonte: Diagnóstico "Perfil do Professor de nível médio da região de Ribeirão Preto".

\begin{tabular}{|c|c|c|c|c|}
\hline Ações & Bio & Geo & Fís & Quí \\
\hline $\begin{array}{l}\text { Tratei o assunto com meus alunos devido a sua importância social e } \\
\text { ambiental. }\end{array}$ & $\begin{array}{c}31 \\
(76,0 \%) \\
\end{array}$ & $\begin{array}{c}42 \\
(91,0 \%) \\
\end{array}$ & $\begin{array}{c}12 \\
(40,0 \%) \\
\end{array}$ & $\begin{array}{c}22 \\
(63,0 \%) \\
\end{array}$ \\
\hline $\begin{array}{l}\text { Enfatizei aspectos jurídicos e as responsabilidades dos donos da } \\
\text { empresa falida. }\end{array}$ & $\begin{array}{c}10 \\
(24,0 \%) \\
\end{array}$ & $\begin{array}{c}13 \\
(28,0 \%) \\
\end{array}$ & $\begin{array}{c}5 \\
(17,0 \%) \\
\end{array}$ & $\begin{array}{c}2 \\
(6,0 \%)\end{array}$ \\
\hline $\begin{array}{l}\text { Enfatizei os prejuízos materiais e as multas que foram aplicadas aos } \\
\text { donos da empresa. }\end{array}$ & $\begin{array}{c}8 \\
(19,0 \%) \\
\end{array}$ & $\begin{array}{c}19 \\
(41,0 \%) \\
\end{array}$ & $\begin{array}{c}2 \\
(6,0 \%) \\
\end{array}$ & $\begin{array}{c}8 \\
(23,0 \%) \\
\end{array}$ \\
\hline $\begin{array}{l}\text { Enfatizei que a legislação ambiental é muito rigorosa no Brasil e que } \\
\text { tal acidente, além das multas, pode conduzir os donos da empresa à } \\
\text { prisão. }\end{array}$ & $\begin{array}{c}8 \\
(19,0 \%)\end{array}$ & $\begin{array}{c}6 \\
(13,0 \%)\end{array}$ & $\begin{array}{c}1 \\
(3,0 \%)\end{array}$ & $\begin{array}{c}2 \\
(6,0 \%)\end{array}$ \\
\hline $\begin{array}{l}\text { Enfatizei o fato de que havia sócios estrangeiros da empresa e que } \\
\text { eles não eram confiáveis. }\end{array}$ & - & $\begin{array}{c}8 \\
(17,0 \%) \\
\end{array}$ & $\begin{array}{c}3 \\
(10,0 \%) \\
\end{array}$ & - \\
\hline $\begin{array}{l}\text { Enfatizei a importância de se dar um tratamento adequado a dejetos, } \\
\text { resíduos e borras industriais para evitar a contaminação de solos e } \\
\text { águas. }\end{array}$ & $\begin{array}{c}30 \\
(73,0 \%)\end{array}$ & $\begin{array}{c}37 \\
(80,0 \%)\end{array}$ & $\begin{array}{c}13 \\
(43,0 \%)\end{array}$ & $\begin{array}{c}19 \\
(54,0 \%)\end{array}$ \\
\hline Enfatizei as relações entre a contaminação e o ciclo da água. & $\begin{array}{c}25 \\
(61,0 \%) \\
\end{array}$ & $\begin{array}{c}33 \\
(71,0 \%) \\
\end{array}$ & $\begin{array}{c}11 \\
(37,0 \%) \\
\end{array}$ & $\begin{array}{c}18 \\
(51,0 \%) \\
\end{array}$ \\
\hline $\begin{array}{l}\text { Enfatizei que muitos fenômenos naturais podem produzir } \\
\text { contaminação semelhante a de um acidente ambiental. }\end{array}$ & $\begin{array}{c}10 \\
(24,0 \%) \\
\end{array}$ & $\begin{array}{c}14 \\
(30,0 \%) \\
\end{array}$ & $\begin{array}{c}8 \\
(27,0 \%) \\
\end{array}$ & $\begin{array}{c}10 \\
(29,0 \%) \\
\end{array}$ \\
\hline $\begin{array}{l}\text { Levantei informações adicionais sobre precipitação, vazão, outras } \\
\text { fontes contaminantes da Bacia do Rio Paraíba do Sul para fazer um } \\
\text { balanço e avaliar o impacto ambiental da região. }\end{array}$ & $\begin{array}{c}7 \\
(17,0 \%)\end{array}$ & $\begin{array}{c}14 \\
(30,0 \%)\end{array}$ & $\begin{array}{c}2 \\
(6,0 \%)\end{array}$ & $\begin{array}{c}5 \\
(14,0 \%)\end{array}$ \\
\hline $\begin{array}{l}\text { Incentivei os alunos a fazerem previsões sobre o impacto ambiental e } \\
\text { os processos de depuração do Rio Paraíba do Sul. }\end{array}$ & $\begin{array}{c}10 \\
(24,0 \%) \\
\end{array}$ & $\begin{array}{c}11 \\
(24,0 \%) \\
\end{array}$ & $\begin{array}{c}1 \\
(3,0 \%) \\
\end{array}$ & $\begin{array}{c}4 \\
(11,0 \%) \\
\end{array}$ \\
\hline $\begin{array}{l}\text { Enfatizei que há limites no conhecimento científico para interpretar os } \\
\text { efeitos da contaminação sobre águas superficiais e subterrâneas. }\end{array}$ & $\begin{array}{c}7 \\
(17,0 \%)\end{array}$ & $\begin{array}{c}11 \\
(24,0 \%)\end{array}$ & $\begin{array}{c}6 \\
(20,0 \%)\end{array}$ & $\begin{array}{l}3 \\
(9,0 \%)\end{array}$ \\
\hline $\begin{array}{l}\text { Enfatizei que nossas explicações e tecnologia sobre a contaminação } \\
\text { mudaram muito nos últimos } 20 \text { anos e hoje temos melhores } \\
\text { condições de buscar procedimentos para mitigar os efeitos } \\
\text { ambientais. }\end{array}$ & $\begin{array}{c}7 \\
(17,0 \%)\end{array}$ & $\begin{array}{c}20 \\
(43,0 \%)\end{array}$ & $\begin{array}{c}5 \\
(17,0 \%)\end{array}$ & $\begin{array}{c}2 \\
(6,0 \%)\end{array}$ \\
\hline Não respondeu & $\begin{array}{c}6 \\
(15,0 \%) \\
\end{array}$ & - & $\begin{array}{c}10 \\
(33,0 \%) \\
\end{array}$ & $\begin{array}{c}9 \\
(26,0 \%) \\
\end{array}$ \\
\hline Não tratei o assunto & $\begin{array}{c}2 \\
(5,0 \%) \\
\end{array}$ & - & $\begin{array}{c}2 \\
(6,0 \%) \\
\end{array}$ & $\begin{array}{c}4 \\
(11,0 \%) \\
\end{array}$ \\
\hline
\end{tabular}


Aspectos mais mencionados pela própria imprensa (prejuízos materiais e sócio-ambientais do acidente) estão entre aqueles tópicos mais citados pelos professores.

Assinalamos, ainda, a ausência de resposta de quase um terço dos professores de Física. Isso sugere que de fato foram os professores que menos mencionaram este fato da atualidade em suas aulas.

\section{Expectativas de formação dos professores do ensino médio}

Aos professores foi solicitado que indicassem tópicos de Geociências para futuras atividades de educação continuada. Tais atividades foram associadas a aspectos que pudessem contribuir para melhorar suas aulas. Não houve lista inicial de tópicos e as indicações foram espontâneas, ou seja, feitas segundo o entendimento e a delimitação de cada professor.

O primeiro aspecto a ser assinalado é o elevado número de professores que não responderam a questão. Como a Tabela 4 revela, quase metade dos respondentes de Biologia, Física e Química não respondeu a pergunta, bem como cerca de um quinto dos docentes de Geografia.

A Tabela 4 revela significativa dispersão de respostas e certa mistura de tópicos que seriam de interesse dos professores independentemente de pertencer ao campo das Geociências. Apesar dessa dispersão, nota-se certa correlação de tópicos e disciplina ministrada pelo professor; dessa maneira, pode-se afirmar que cada um dos quatro universos que fizeram parte do levantamento possui necessidades específicas em termos de conteúdo. Professores de Biologia indicam que seu interesse situa-se em assuntos de interface com a Geologia, por exemplo, origem da Terra e ecologia. Docentes de Geografia citam tópicos de Geociências que notoriamente apresentam problemas de ensino e dizem respeito ao entendimento da Terra como corpo cósmico e sua representação visual; isso é sugerido por cerca de um quinto da amostra que indica cartografia como alvo de atividades de educação continuada. Outros temas citados dizem respeito a processos e produtos de fenômenos geológicos, tais como tectônica de placas e estruturas geológicas. Os de Química se aproximam da Geologia pelos aspectos próximos da química analítica (mineralogia, metais, mineração, geoquímica). No que diz respeito a estes professores observa-se porcentuais muito mais baixos de indicações quando comparados aos colegas de Geografia e Biologia. Docentes de Física, por outro lado, manifestam maior interesse, antes de mais nada, em atividades de laboratório do que em tópicos de Geociências; quando mencionam tópicos específicos de conteúdo, estes fazem parte do domínio da Física e podem ser pensados como propriedades do corpo cósmico do planeta Terra.
Questões ambientais, assuntos de atualidade e temas correlatos figuram como outro grupo relevante de menções feitas espontaneamente pelos professores. O número de sugestões equivale àquelas feitas sobre tópicos específicos de interesse de cada um dos universos (descritas anteriormente).

Apesar da dispersão percebe-se que os professores estão preocupados com problemas do ambiente e isso aproxima conteúdos e programas do interesse em contextualizar o ensino (o que é coerente com os resultados expostos na Tabela 2).

Parcela das respostas revela um esforço de aperfeiçoar atividades e procedimentos didáticos. Sugestões de explorar novos materiais didáticos e recursos de informática achamse diretamente vinculados a tais preocupações.

\section{DISCUSSÕES}

O primeiro aspecto que chama atenção na amostra examinada é o significativo desnível de formação acadêmica entre um grupo altamente qualificado e profissionais cuja formação está muito distante da disciplina que ministram. Tal fator pode gerar descompassos entre o trabalho de diferentes professores para uma mesma turma de estudantes. O resultado pode ser desestímulo ao estudo e ao aperfeiçoamento profissional.

Embora a LDB tenha alterado significativamente o discurso oficial voltado para o ensino médio isso não parece ter influenciado as preocupações dos professores. Na opinião dos professores as mudanças legais parecem restritas aos PCN mas sua interpretação é bastante dispersa. Isso sugere que as motivações para desenvolver um ensino mais contextualizado e mais vinculado ao cotidiano dos alunos não emerge dos textos legais. De fato, trata-se de certo conjunto de idéias que foi incorporado ao ensino desejado pelos professores. No entender destes, tal enfoque conduz a uma aprendizagem mais sólida e consistente.

Ao mesmo tempo, tal ideal de ensino é perseguido com grande dificuldade. É nítida a preocupação da maioria dos professores em contextualizar os assuntos tratados por suas disciplinas. Isso é sugerido tanto pelas respostas dadas aos quesitos mais freqüentemente adotados em suas aulas, quanto à preocupação de abordar temas da atualidade (intensamente citados pela imprensa) em suas aulas. Dos professores que já responderam ao diagnóstico, são os de Geografia e de Biologia aqueles que sugerem estar mais envolvidos e atentos a possíveis vínculos entre problemas ambientais e contextualização do ensino. Podemos afirmar que há conteúdos contextualizados em parcela significativa das disciplinas de nível médio. 
Tabela 4. Tópicos solicitados pelos professores para aprofundamento em Geociências. Organizado por disciplina. Apresentado em número absoluto e porcentagem da amostra de cada disciplina. Itens indicados espontaneamente. Bio - professores de Biologia. Geo - professores de Geografia. Fís - professores de Física. Quí - professores de Química. Porcentagens aproximadas. Fonte: Diagnóstico "Perfil do Professor de nível médio da região de Ribeirão Preto".

\begin{tabular}{|c|c|c|c|c|c|c|c|c|}
\hline Tópicos & & io & & eo & & ís & & Quí \\
\hline Não respondeu & 18 & $44,0 \%$ & 10 & $22,0 \%$ & 14 & $47,0 \%$ & 15 & $43,0 \%$ \\
\hline Não sei & - & - & - & - & 1 & $3,0 \%$ & - & - \\
\hline Origem e evolução da Terra & 9 & $22,0 \%$ & - & - & - & - & 2 & $6,0 \%$ \\
\hline Cartografia & - & - & 9 & $19,0 \%$ & - & - & - & - \\
\hline Geologia & - & - & 7 & $15,0 \%$ & - & - & - & - \\
\hline Geografia Física & - & - & 6 & $13,0 \%$ & - & - & - & - \\
\hline Ecologia & 4 & $10,0 \%$ & - & - & 2 & $6,0 \%$ & - & - \\
\hline Climatologia & - & - & 3 & $6,0 \%$ & - & - & - & - \\
\hline Astronomia & - & - & 2 & $4,0 \%$ & - & - & - & - \\
\hline Bioquímica & 2 & $4,9 \%$ & - & - & - & - & - & - \\
\hline Genética e Citologia & 1 & $2,4 \%$ & - & - & - & - & - & - \\
\hline Meteorologia & - & - & 1 & $2,0 \%$ & - & - & - & - \\
\hline Mineralogia & - & - & - & - & - & - & 1 & $3,0 \%$ \\
\hline Vulcanismo & - & - & 1 & $2,0 \%$ & - & - & - & - \\
\hline Geomorfologia & - & - & 1 & $2,0 \%$ & - & - & - & - \\
\hline Tópicos de Geociências & - & - & - & - & 1 & $3,0 \%$ & - & - \\
\hline Termometria & - & - & - & - & 3 & $10,0 \%$ & - & - \\
\hline Magnetismo & - & - & - & - & 2 & $6,0 \%$ & - & - \\
\hline Terra & - & - & - & - & 1 & $3,0 \%$ & - & - \\
\hline Energia & - & - & - & - & 1 & $3,0 \%$ & - & - \\
\hline Corpo humano & - & - & - & - & 1 & $3,0 \%$ & - & - \\
\hline Minerais, metais e obtenção & - & - & - & - & - & - & 2 & $6,0 \%$ \\
\hline Composição da Terra e Sol & - & - & - & - & - & - & 1 & $3,0 \%$ \\
\hline Ciclos do carbono e nitrogênio & - & - & - & - & - & - & 1 & $3,0 \%$ \\
\hline Mineração & - & - & - & - & - & - & 1 & $3,0 \%$ \\
\hline Fósseis & 2 & $4,9 \%$ & - & - & - & - & - & - \\
\hline Tópicos de pedologia & - & - & 1 & $2,0 \%$ & - & - & 1 & $3,0 \%$ \\
\hline Placas tectônicas & - & - & 4 & $9,0 \%$ & - & - & - & - \\
\hline Estruturas geológicas & - & - & 3 & $6,0 \%$ & - & - & - & - \\
\hline Fuso horário & - & - & 3 & $6,0 \%$ & - & - & - & - \\
\hline Planejamento urbano & - & - & 1 & $2,0 \%$ & - & - & - & - \\
\hline Atualidades & 4 & $10,0 \%$ & 2 & $4,0 \%$ & - & - & - & - \\
\hline Poluição ambiental & - & - & 1 & $2,0 \%$ & - & - & 6 & $17,0 \%$ \\
\hline Efeito estufa e clima & 3 & $7,0 \%$ & - & - & 1 & $3,0 \%$ & 2 & $6,0 \%$ \\
\hline Meio ambiente & 2 & $4,9 \%$ & 8 & $17,0 \%$ & - & - & 4 & $11,0 \%$ \\
\hline Recursos hídricos & 2 & $4,9 \%$ & 5 & $11,0 \%$ & 1 & $3,0 \%$ & 3 & $9,0 \%$ \\
\hline Resíduos sólidos & - & - & 3 & $6,0 \%$ & 1 & $3,0 \%$ & 1 & $3,0 \%$ \\
\hline Contaminação & - & - & 1 & $2,0 \%$ & - & - & 1 & $3,0 \%$ \\
\hline Problemas ambientais & 4 & $9,8 \%$ & 1 & $2,0 \%$ & 3 & $10,0 \%$ & - & - \\
\hline Problemas ambientais locais & 1 & $2,4 \%$ & - & - & - & - & - & - \\
\hline Fome & 2 & $4,9 \%$ & - & - & - & - & - & - \\
\hline Drogas & 1 & $2,4 \%$ & - & - & - & - & - & - \\
\hline Tópicos de integração de disciplinas & 2 & $4,9 \%$ & 1 & $2,0 \%$ & - & - & - & - \\
\hline Preparo para usar laboratório & - & - & - & - & 4 & $13,0 \%$ & 1 & $3,0 \%$ \\
\hline Materiais didáticos & - & - & 1 & $2,0 \%$ & 1 & $3,0 \%$ & 2 & $6,0 \%$ \\
\hline Informática aplicada ao ensino & - & - & 1 & $2,0 \%$ & 1 & $3,0 \%$ & - & - \\
\hline Cotidiano no ensino & - & - & 1 & $2,0 \%$ & 3 & $10,0 \%$ & - & - \\
\hline
\end{tabular}


As respostas dadas pelos professores sugerem que tais conteúdos são tratados com baixo grau de aprofundamento. A opinião dos professores, de que os alunos fracamente conseguem relacionar disciplinas e realidade, conduz à idéia de que, ao não ultrapassar certos limites de aprofundamento, a contextualização está sendo banalizada e pouco ajuda a formar o senso crítico dos alunos ou um entendimento claro sobre como cada conhecimento científico (de cada disciplina) contribui para desvendar a realidade.

É importante chamar atenção, ainda, para o fato de que os professores possuem clareza de tal deficiência do ensino ao sugerir que seus alunos não são capazes de compreender a natureza do conhecimento científico, bem como não estabelecem relações desses conteúdos contextualizados e sua vida ou a realidade.

A dispersão de tópicos sugeridos de Geociências e sua diferenciação por disciplina é congruente com as considerações de Shulman (1987) sobre como se forma o conhecimento do professor: apoiado, ao mesmo tempo, na prática e em sua formação inicial.

Tais tópicos e o isolamento em campos ou assuntos específicos revela incapacidade para integrar essas partes no estudo da Terra. Sobretudo os itens relativos a problemas ambientais assinalam certa percepção fragmentada do conhecimento geológico.

Podemos depreender, ainda, que os tópicos de Geociências listados pelos professores sugerem o programa praticado ou almejado pelos docentes. São notórias as dificuldades de professores de Biologia para tratar tempo geológico e de Geografia para ensinar a ler mapas; embora parcela dos professores afirme ter tratado o acidente ambiental em suas aulas, na opinião deles mesmos isso foi feito com baixo grau de aprofundamento. Seria, portanto, coerente que os professores almejassem fazer capacitações que permitissem avançar seu conhecimento para tratar com mais propriedade os temas citados e, dessa maneira, obter resultados mais favoráveis de aprendizagem.

\section{CONCLUSÕES}

Estamos surpresos em relação à baixa expectativa dos professores quanto ao resultado de suas aulas. Se esses em sua maioria indicam que iniciam a transposição didática a partir de fatos da realidade, não esperam que seus alunos sejam capazes de aplicar os conhecimentos explorados em sala de aula para sua vida prática (Tabela 2), apresentam ainda o mesmo nível de resposta em relação à capacidade dos estudantes de diferenciarem as explicações científicas da realidade.

As respostas dadas pelos professores quanto aos procedimentos mais mencionados para tratar o acidente da
Florestal Cataguazes (importância do tratamento de resíduos, relações do ciclo da água) não são compatíveis com as "competências e habilidades" de contextualização sócio-cultural preconizadas nos PCN (sobretudo aqueles de Biologia, Química e Física). Isso não permite inferir que haja o desenvolvimento de capacidades de análise pelos alunos do nível médio.

As respostas dos professores quanto aos procedimentos de ensino vinculados à capacidade dos alunos de aplicar os conhecimentos escolares à realidade e perceber a diferença entre Ciência e a vida mostram que "competências e habilidades” de contextualização sócio-cultural preconizadas nos PCN pela Biologia, Geografia, Química e Física não estão sendo realizadas pelos professores.

O tratamento dado ao acidente da Florestal Cataguazes sugere que a maioria dos professores está preocupada em contextualizar os conteúdos de ensino mas o faz somente dentro do senso comum. Aprofundamentos adicionais, tais como: extrapolações e comparações com outros fenômenos, avaliação que depende de estudos e informes adicionais, elaboração de hipóteses e modelamento do fenômeno ocorrido, explicitação do caráter histórico das explicações e modelos da Ciência, perspectiva histórica e estabelecimento de vínculos de Ciência e tecnologia, não são desenvolvidos pelos professores.

As respostas dadas pelos professores indicam que a idéia de Ciência que possuem sobre sua disciplina, muitas vezes, acha-se ligada à concepção de que a Ciência não é neutra e que deve-se tratar conhecimento científico e tecnológico conjuntamente. Isso é coerente com certas perspectivas preconizadas pelos PCN para facilitar vínculos do contexto ambiental e conteúdos das disciplinas escolares. Ao mesmo tempo, a tabulação dos resultados não sugere uma idéia de Ciência dinâmica que muda seus conceitos ao longo do tempo e que, portanto, possui uma história.

Os professores parecem ter incorporado a concepção de que fatos da atualidade devem ilustrar aulas ou ocupar o lugar de conteúdos previamente planejados. Abordagens e perspectivas mais críticas não foram encontradas na maioria dos professores que responderam os questionários. Portanto a contextualização parece restrita à ilustração de algumas aulas e não tem propiciado condições favoráveis à interdisciplinaridade.

A precária, limitada e fragmentada concepção de Geociências não capacita os professores para desenvolver de forma sistêmica, hipotética e temporal a desejável integração de informações ambientais na perspectiva geológica, sob abordagem de uma natureza em permanente transformação. Isso sugere a necessidade de se desenvolver metodologias para avançar o conhecimento dos professores sobre o planeta. 


\section{AGRADECIMENTOS}

Os autores reconhecem a colaboração dos colegas Jesus Aparecido Ribeiro e Maria Ângela Garofalo (da DERRP), os professores que responderam os questionários e a auxiliar de pesquisa Rosana Valentim da Silva.

\section{REFERÊNCIAS BIBLIOGRÁFICAS}

AMARAL, I. A. Em busca da planetização do ensino de ciências para a educação ambiental. 1995. 2 v. Tese (Doutorado) - Faculdade de Educação, Universidade Estadual de Campinas, Campinas.

ANGUITA, F. Geología y ciencias de la tierra: etimología y un poco de historia. Enseñanza de las Ciencias de la Tierra, v. 4, n. 3, p. 177-180, dic. 1996.

BARRETTO, E. S. S. Tendências recentes do currículo do ensino fundamental do Brasil. In: BARRETTO, E. S. S. (Org.). Os currículos do ensino fundamental para as escolas brasileiras. São Paulo: Autores Associados: Fundação Carlos Chagas, 1998. p. 5-42.

BEZZI, A. What is this thing called Geoscience? Epistemological dimensions elicited with the repertory grid and their implications for scientific literacy. Science Education, v. 83, n. 6, p. 675-700, Nov. 1999.

BRASIL. Ministério da Educação. Secretaria de Educação Média e Tecnológica. Parâmetros curriculares nacionais: ensino médio. Brasília: Ministério da Educação, 1999. 364 p.

BRASIL. Ministério da Educação. Secretaria de Educação Média e Tecnológica. Diretrizes curriculares nacionais para o ensino médio. Brasília: MEC/SENTEC, 1998.

GIMENO SACRISTÁN, J.; PÉREZ GÓMEZ, A. I. Compreender e transformar o ensino. Porto Alegre: Artmed, 1998. 396 p.

HURD, Paul DeHart. Scientific literacy: new minds for a changing world. Science Education, v. 82, n. 3, p. 407-416, Jun. 1998.

LOPES, A. C. Os parâmetros curriculares nacionais para o ensino médio e a submissão ao mundo produtivo: o caso do conceito de contextualização. Educação \& Sociedade, Campinas, v. 23, n. 80, p. 389-403, 2002.

MATTHEWS, M. R. James T. Robinson's account of philosophy of science and science teaching: some lessons for today from the 1960s. Science Education, v. 81, n. 3, p. 295-315, Jun. 1997.

McGINNIS, J. R.; SIMMONS, P. Teacher's perspectives of teaching science-technology-society in local cultures: sociocultural analysis. Science Education, v. 83, n. 2, p. 179-211, Mar. 1999.

PACHECO, J. A. Políticas curriculares: referenciais para análise. Porto Alegre: Artmed, 2003.143 p.

PALMA FILHO, J. C. A Reforma curricular da Secretaria de Educação do Estado de São Paulo para o ensino de $1^{\circ}$ grau (1983-1987: uma avaliação crítica). 1989. 3 v. Dissertação (Mestrado) - Pontifícia Universidade Católica de São Paulo, São Paulo.

ROBINSON, J. T. Science teaching and nature of science: orig. 1965. Science \& Education, v. 7, n. 6, p. 617-634, Nov. 1998.

ROJERO, F. F. ¿Uma asignatura sistémica o sistemática? Enseñanza de las Ciencias de la Tierra, v. 8, n. 3, p. 189-196, 2000.

SAMPAIO, M. M. F. O cotidiano escolar face às políticas educacionais. Araraquara: JM Editora, 2002. 142 p.

SEADE. Fundação Sistema Estadual de Análise de Dados. Demografia Municipal. Disponível em:

http://www.seade.gov.br/. Acesso em: 03 out. 2005.

SENNA, A. C. Legislação brasileira do ensino secundário de 1901 a 1939. Rio de Janeiro: Central, 1939.

SHULMAN, L. S. Knowledge and teaching: foundations of the new reform. Harvard Educational Review, v. 57, n. 1, p. 1-22, Feb. 1987.

SICCA, N. A. L. A contextualização no ensino médio: a química como objeto de ensino. In: GONÇALVES, M. F. C. (Org.). Educação escolar: identidade e diversidade. Florianópolis: Insular, 2003. p. 143-168.

SOLBES, J.; VILCHES, A. STS interactions and the teaching of physics and chemistry. Science Education, v. 81, n. 4, p. 377-386, Jul. 1997. 